\title{
Characterization of friction properties at the workmaterial/cutting tool interface during the machining of randomly structured carbon fibers reinforced polymer with carbide tools under dry conditions
}

\author{
Olga Klinkova ${ }^{\mathrm{a}, *}$, Joël Rech ${ }^{\mathrm{a}}$, Sylvain Drapier ${ }^{\mathrm{b}}$, Jean-Michel Bergheau ${ }^{\mathrm{a}}$ \\ ${ }^{a}$ University of Lyon, Ecole Nationale d'Ingénieurs de Saint-Etienne, Laboratoire de Tribologie et Dynamique des Systèmes, CNRS UMR 5513, 58 rue Jean Parot, \\ Saint-Etienne 42000, France

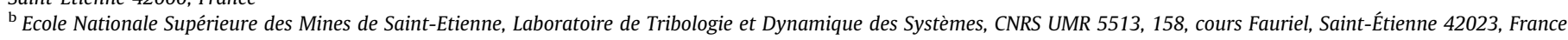

Carbon fiber reinforced polymers (CFRP) are increasingly employed within the aerospace industry, particularly within the aircraft sector. However, machining of fiber reinforced composites can be quite complex, first due to the inherent heterogeneity resulting from the reinforcements/matrix assembly and second due to the presence of high modulus/high strength fibers. Therefore, a lot of Finite Element models have been developed in order to understand their material removal mechanisms. Among the scientific issues faced by these works, the identification of friction coefficients between CFRP and cutting tool materials remains a strategic field of research. This paper aims at characterizing the friction properties between composite and cutting tool materials. More precisely, the paper focuses on the context of a randomly structured CFRP, called HEXTOOL ${ }^{\mathrm{TM}}$, machined with a carbide tool under dry conditions. The specific tribological conditions during machining of such heterogeneous materials are discussed in the paper, especially the configuration of the tribosystem ('opened tribosystem'). The great lack of friction coefficient is mainly due to the absence of relevant tribometers simulating the tribological conditions occurring in cutting. This paper presents the development of a new tribometer designed to simulate conditions corresponding to machining of randomly structured CFRP materials. It provides quantitative values of friction coefficient and heat partition coefficient depending on sliding velocities. This work has revealed that friction coefficients are very low in dry regime compared to those obtained in metal cutting. Moreover, experimental results confirm that friction coefficient decreases from 0.25 to 0.1 when sliding velocity increases. Finally this works establishes that a TiN layer deposited on carbide tools is not able to modify friction properties.

\section{Introduction}

Composite materials such as carbon fiber reinforced polymer (CFRP) are increasingly used in industrial fields, such as aerospace, aircraft, automobile and sports, owing to their advantages in mechanical properties (higher specific strength and stiffness) compared to their low density. Most of composite products are made to near-net-shape. However, machining processes such as milling or drilling are frequently used to achieve dimensional tolerance and assembly requirements. Previous works have shown that machining composite materials differs significantly from machining conventional metals (matrix cracking, fiber fracture, interlaminar delamination, etc.) due to the material properties of the fibers and to their heterogeneous structure

\footnotetext{
* Corresponding author.

E-mail address: klinkova@enise.fr (O. Klinkova).
}

[1-3]. The important material abrasiveness leads manufacturers to make use of hard substrates to limit rapid tool wear.

Productivity improvement of machining operations requires the optimization of tool geometry and cutting conditions. In parallel, a lot of attention has to be paid on the surface integrity of machined parts, since cutting may induce functional problems [1]. Numerical modeling of cutting is a way to enable this optimization and to ensure the quality of machined surfaces. Among the key input data necessary to perform numerical models, a friction model between composite material and cutting tool material is required. However, obtaining realistic friction data in CFRP cutting remains an issue for several reasons. On one hand, due to the kinematic of a cutting operation, the workmaterial is separated in two parts (Fig. 1): the chip and the machined surface. From the chip point of view, the contact surface is called the secondary shear zone. From the machined surface point of view, the contact surface is called the rubbing zone or the third shear zone. In both cases, the surface of the workmaterial will be in 

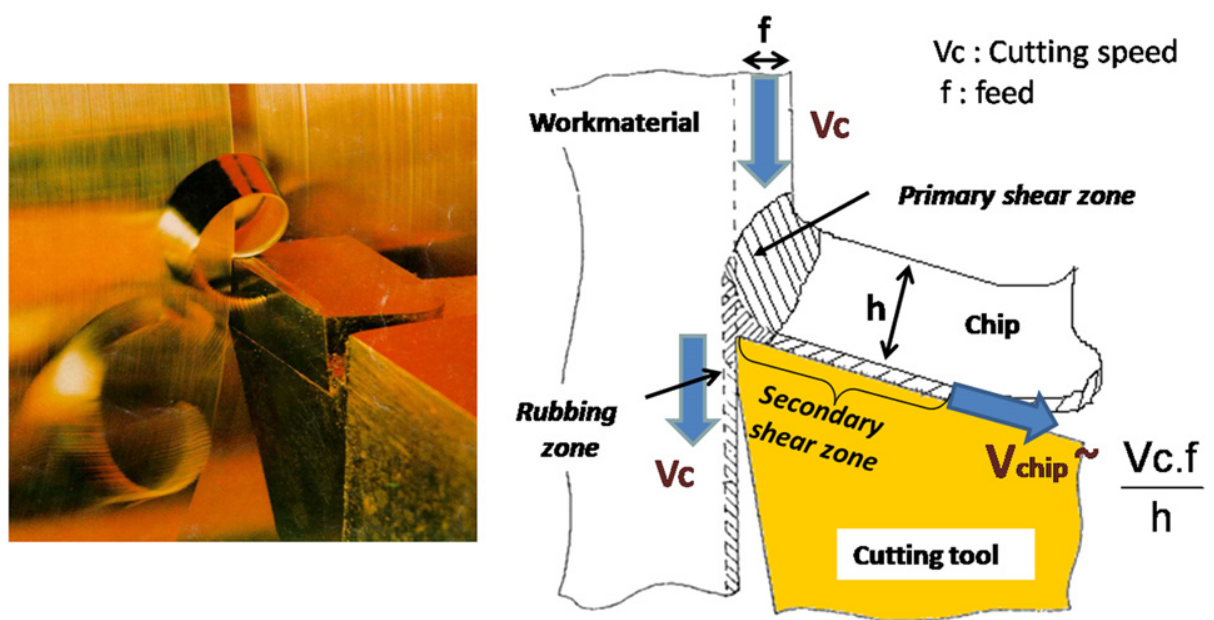

Fig. 1. Basic modeling of metal cutting.
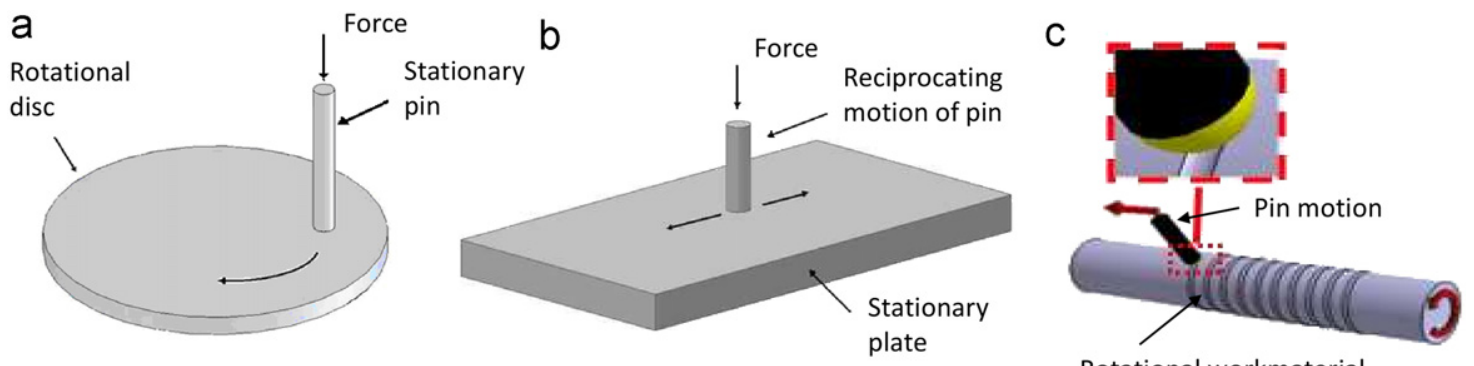

Fig. 2. (a) Closed tribosystem (pin on disc); (b) linear opened tribosystem [4]; (c) rotary opened tribosystem [22].

contact with the cutting tool material during a very short period (typically some milliseconds) under very high pressure and velocity. Moreover, this surface will no longer be in contact with the cutting tool material. From the cutting tool point of view, there is a continuous flow of new workmaterial in these zones. This tribological situation corresponds to a so-called: 'opened tribosystem', which will be described below in the paper. The wide majority of tribometers are 'closed tribosystem', such as pin on disc systems, where a pin always rubs on the same part of a material (Fig. 2a). This situation is not suitable to provide relevant data for cutting applications. Indeed, there are very few tribometers able to simulate such 'opened tribosystem' (Fig. 2b and c). On other hand, a CFRP is a heterogeneous material made of several orientated layers in the case laminated structure, or of several short fiber bundles in the case of randomly structured structure. For each layer or short fiber bundles, fibers are oriented in a defined direction. Therefore, a cutting edge has to cut fibers having various orientations. It is shown by [4] that the layer orientation may influence friction at the tool/CFRP interface.

In the scientific literature, a lot of efforts have been made recently to initiate the Finite Element Modeling of composite materials in order to understand the local material removal mechanisms. The wide majority of these works considers the Coulomb model with a constant coefficient [5-9] or does not consider any friction [10-13]. The values of the friction coefficient reported vary between 0.1 [4], 0.15 [7], 0.3 [5,9,14] and 0.5 [7,15] depending on the couple of materials involved (tool material/ nature of composite material). Other authors consider a coefficient of friction with respect to fibers orientation $[9,16]$ from 0.09 to 0.9 . Finally [4] has shown that the presence of a cutting fluid can reduce the friction coefficient from 0.1 to 0.06 during machining of laminated CFRP with diamond cutting tools.
The identification conditions of friction coefficients are rarely explained in details, this makes it difficult to apply for other investigations. In the field of tribology, several works consider the friction of composites against metals or sapphire, which are not relevant substrates for cutting tools $[17,18]$. Consequently, such values are not usable to model cutting processes with carbide tools as considered in the present work.

Some works such as $[8,9]$ have performed pin on disc tests with High Speed Steel pins (HSS) and a Glass FRP disc, which is not a relevant tribological test as mentioned previously. Additionally, the testing conditions (sliding velocity $\sim 0.5 \mathrm{~m} / \mathrm{min}$ ) do not make sense for CFRP machining. For example, [19] reports that cutting speeds usually applied during machining of CFRP are in the range from 10 to $40 \mathrm{~m} / \mathrm{min}$. Other works such as Ref. [4] have characterized the friction coefficients between a laminated CFRP and a diamond tool under sliding velocities up to $20 \mathrm{~m} / \mathrm{min}$.

Unfortunately most of the papers use friction coefficients which have not been identified by any friction test $[5,6,7,14,15]$. Nonetheless, only few papers have applied relevant friction conditions (i.e. measured with an opened tribosystem). It is only possible to mention the work done by Mondelin et al. [4] who have developed an opened tribometer specifically designed for laminated CFRP. However this system is limited to perform tests under sliding velocities up to $20 \mathrm{~m} / \mathrm{min}$, which is quite low compared to industrially expected cutting speeds (up to $100 \mathrm{~m} / \mathrm{min}$ ).

As a summary, it can be stated, that there is no data already published in a scientific journal presenting friction coefficients for a randomly structured CFRP and a carbide tool, that have been performed on an opened tribometer under high sliding velocities up to $120 \mathrm{~m} / \mathrm{min}$. Hence, there is a high need to develop a tribometer able to simulate the tribological conditions occurring 
during the machining of randomly structured CFRP materials. Such tribometers presented in Fig. $2 \mathrm{~b}$ have already been developed to characterize friction coefficients in metal cutting [20-22]. Consequently, the objective of this work is to adapt the principle of this tribometer to characterize friction coefficients between randomly structured CFRP and carbide tools for a large range of sliding velocities.

\section{Description of the experimental work}

\subsection{Description of CFRP structure}

The HexTOOL ${ }^{\mathrm{TM}}$ material is a new composite solution for manufacturing molds to produce aerospace components. HexTOOL $^{\mathrm{TM}}$ uses Hexcel's established HexMC ${ }^{\circledR}$ technology. This product consists of high strength carbon fiber, with a nominal fiber volume of 60\%, and HexPly M61 BMI (bismaleimide) resin, at $40 \%$ resin content, cured at $190{ }^{\circ} \mathrm{C}$ in autoclave under 7 bar pressure. This is an alternative to conventional tooling materials, including metal. Specifically developed for tooling, the M61 resin is toughened and modified to reduce resin flow so that the preimpregnated sections stay in place during tool cure to maintain their quasi-isotropic fiber distribution (Fig. 3). Compared to epoxy resins, this provides superior machinability without distortion, permitting the manufacture of tools with complex shapes and tight tolerances. The HexTOOL ${ }^{\mathrm{TM}}$ structure is presented in Fig. 3, where one can see the unidirectional carbon fiber pre-impregnated bundles of $50 \mathrm{~mm}$ length and $8 \mathrm{~mm}$ width presented in a quasi-isotropic orientation. The manufacturing process of composite components generally involves the lay-up of pre-impregnated bundles onto a tool surface, vacuum bagging followed by autoclave cure (Fig. 3). The lay-up process aims at obtaining the desired composite mold thickness; it is done by stacking several plies. The autoclave curing induces resin reticulation by applying the temperature cycle.

Once the composite mold is cured, the HexTOOL ${ }^{\mathrm{TM}}$ mold has a rough surface. A machining operation is necessary so as to obtain a smooth and accurate surface. Fig. 4 shows an image of a section at a mesoscopic scale (view B) and at a microscopic scale (view C). The wavy structure is induced by the stacking of the randomly distributed fiber bundles during the lay-up process. After a machining operation, the structure appears as marbled without any specific orientation of fibers (view A). Hence machined surfaces can be considered as randomly structured.

\subsection{Experimental set-up}

The principle of the open tribometer (Fig. 5) has already been applied and validated in several previous works [20-22]. The workmaterial is simulated through a cylindrical bar made of HexTOOL ${ }^{\mathrm{TM}}$ (its manufacturing will be described below). A turning operation followed by a belt finishing operation is performed on the HexTOOL ${ }^{\mathrm{TM}}$ cylindrical bar in order to obtain a low surface roughness and a constant surface before each test. Cutting tools are simulated through pins made of cemented carbide with a similar grade to the one used for cutting tools dedicated for composite material machining ( $90 \%$ WC- $10 \%$ Co-average grain size $\sim 0.8 \mu \mathrm{m}$ ).

In order to eliminate the potential influence of surface roughness, pins have been polished to reach a low surface roughness ( $\mathrm{Ra}<0.3 \mu \mathrm{m})$ which is coherent with a typical surface roughness on a finely ground carbide cutting tool. The pin is maintained by an instrumented pin-holder which is able to provide data about the instantaneous heat flow $(\phi)$ entering into the pin. The detailed information about heat flow measuring system can be found in [21]. The pin-holder is fixed onto a dynamometer in order to measure the normal force $F_{n}$ and the tangential force $F_{t}$ (macroscopic forces). The apparent friction coefficient $\mu_{\text {app }}$ is provided by the ratio between the tangential and the normal forces (Fig. 7), taken as an average value in the stable zone

$\mu_{\text {app }}=\frac{F_{t}}{F_{n}}$

The term 'apparent friction coefficient' is used since it differs significantly from the 'interfacial friction coefficient' induced by
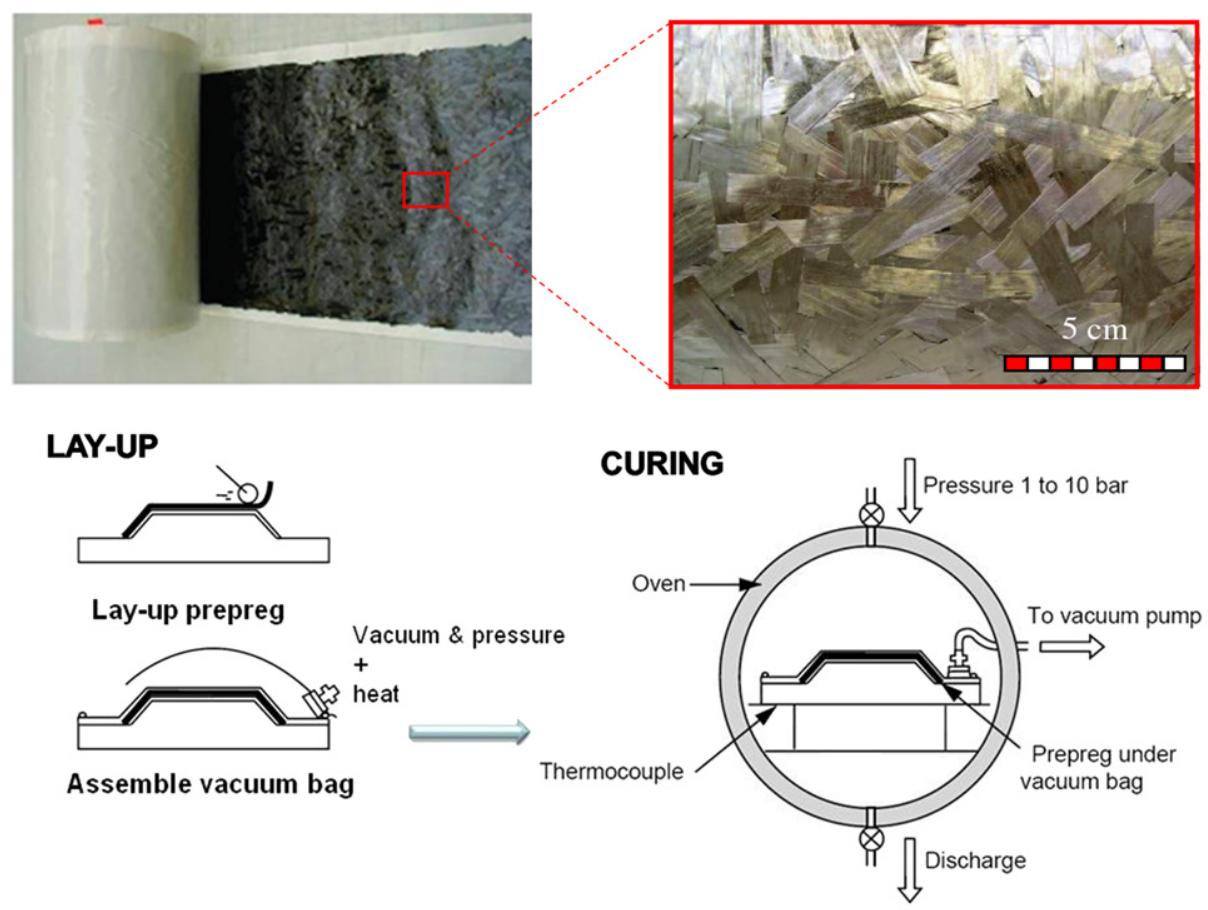

Fig. 3. Manufacture of a part made of the $\mathrm{HexTOOL}^{\mathrm{TM}}$ composite material [28]. 


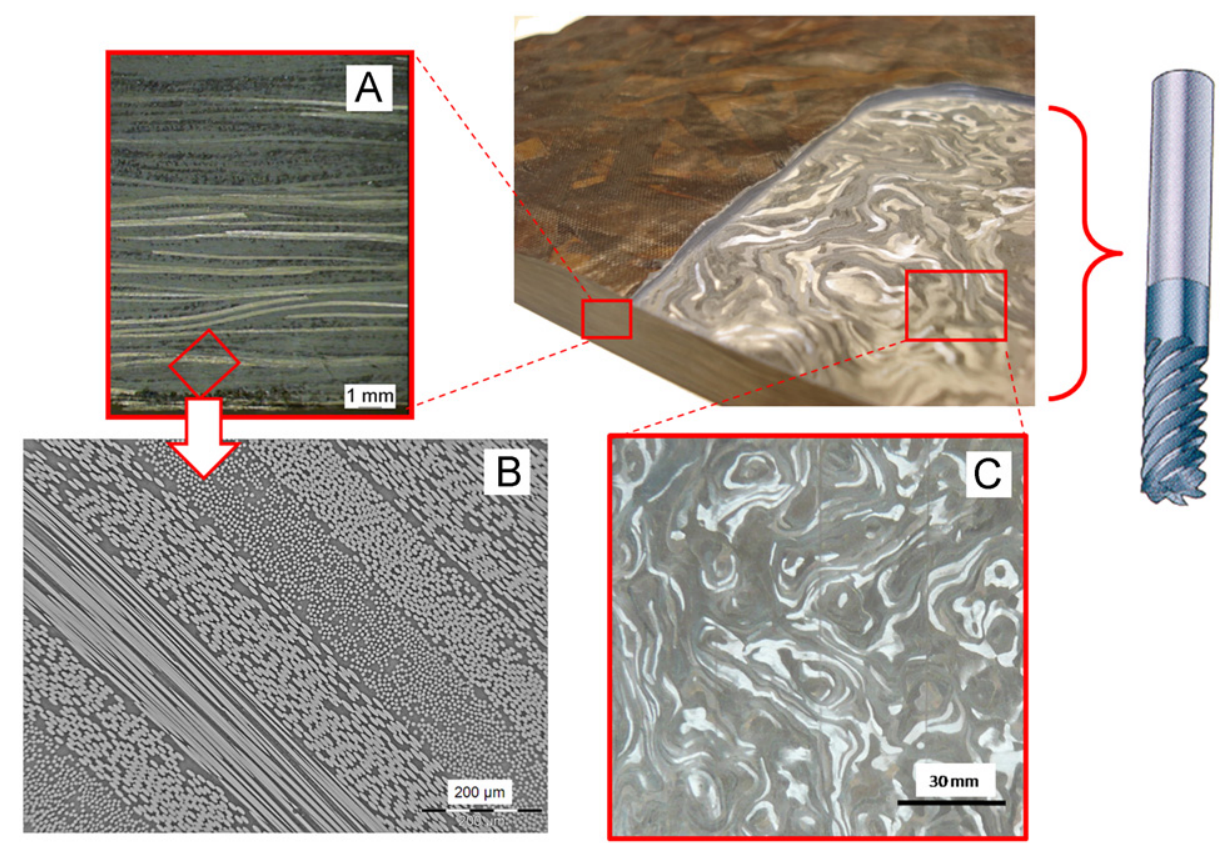

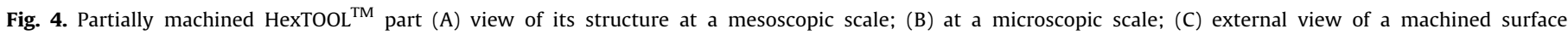
at a macroscopic scale.

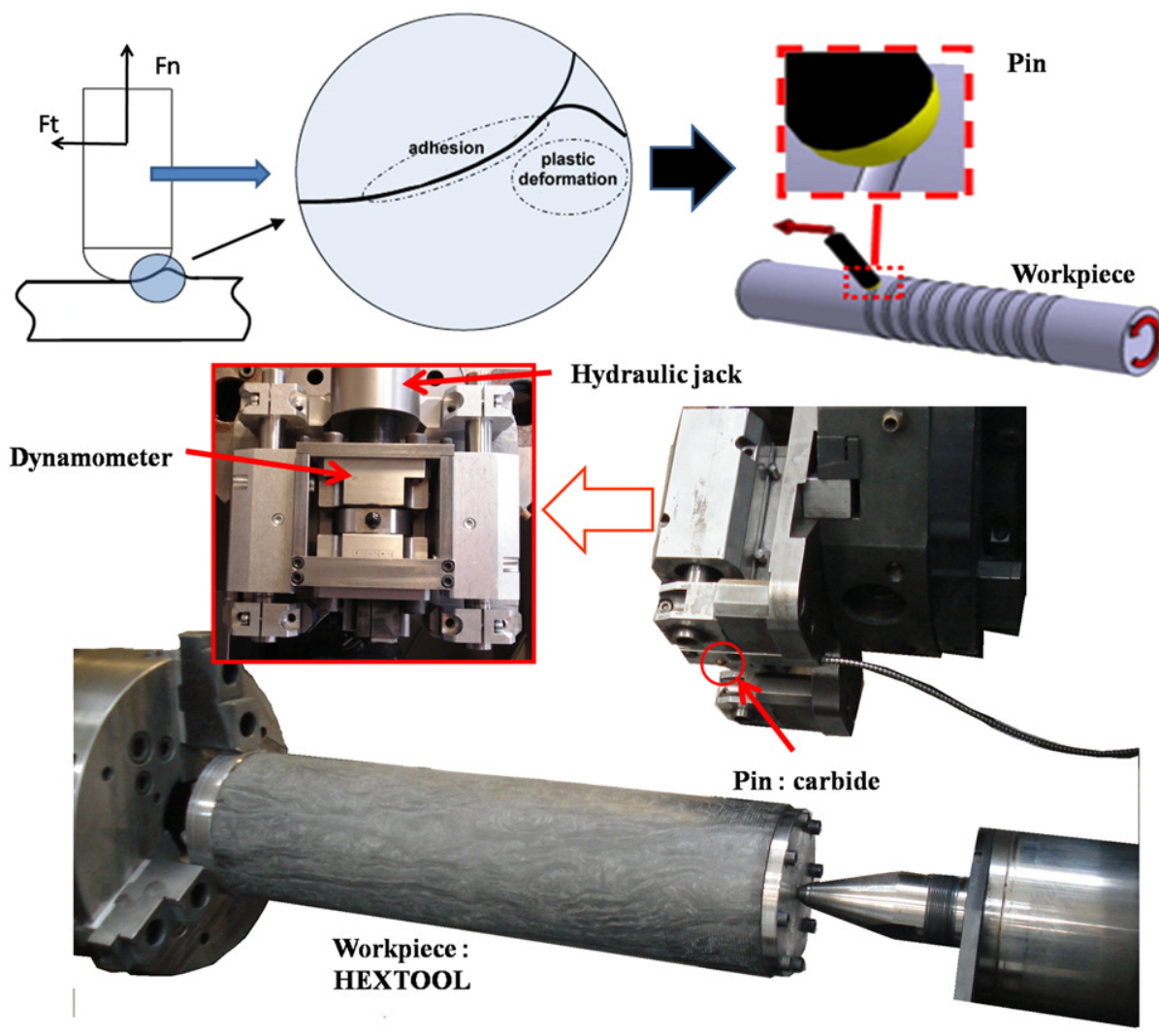

Fig. 5. Description of the tribometer.

adhesion at the pin/workmaterial interface. Indeed the macroscopic forces measured by the tribometer include friction phenomena (adhesion $\rightarrow \mu_{a d h}$ ), elastic deformation and plastic deformation of the workmaterial, which cannot be neglected under such severe contact conditions $\left(F_{n} \sim 600 \mathrm{~N}\right)$. The identification of the evolution of $\mu_{a d h}$ with the present data will be presented later in the paper.
Manufacturing a tube made of $\mathrm{HexTOOL}^{\mathrm{TM}}$ (Fig. 6) involves the same autoclave process as shown previously (Fig. 3). A tube having a rough shape is obtained. Then extremities are machined in order to facilitate clamping on the tribometer. As mentioned previously, the cylindrical surface is turned and belt finished before performing any friction tests. The same marbled surface as 

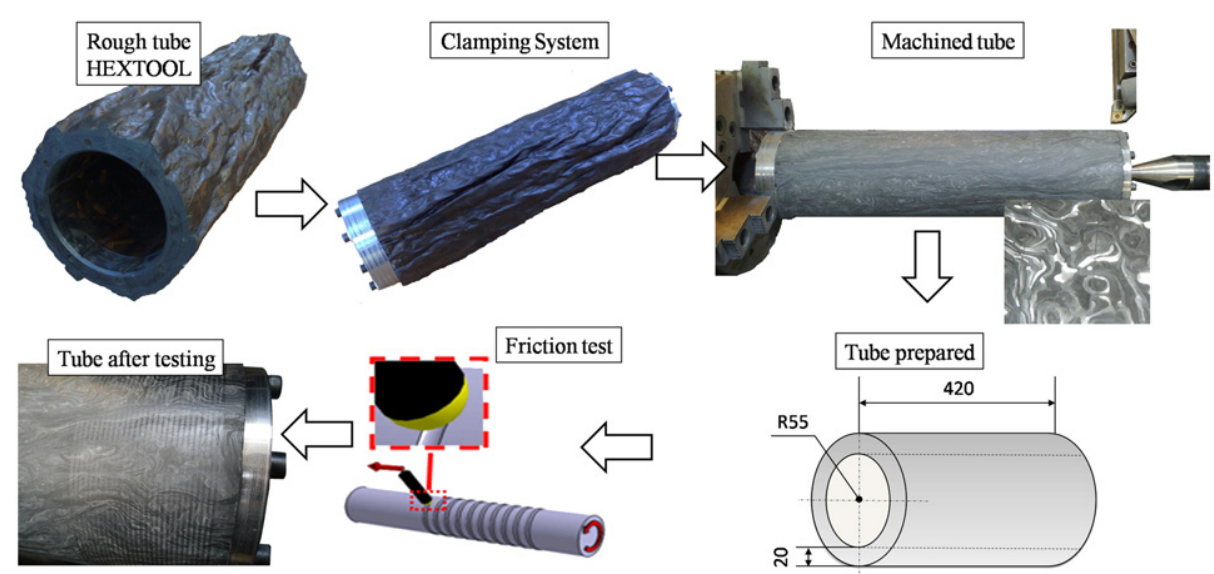

Fig. 6. Preparation of cylindrical parts made of $\operatorname{HexTOOL}^{\mathrm{TM}}$.
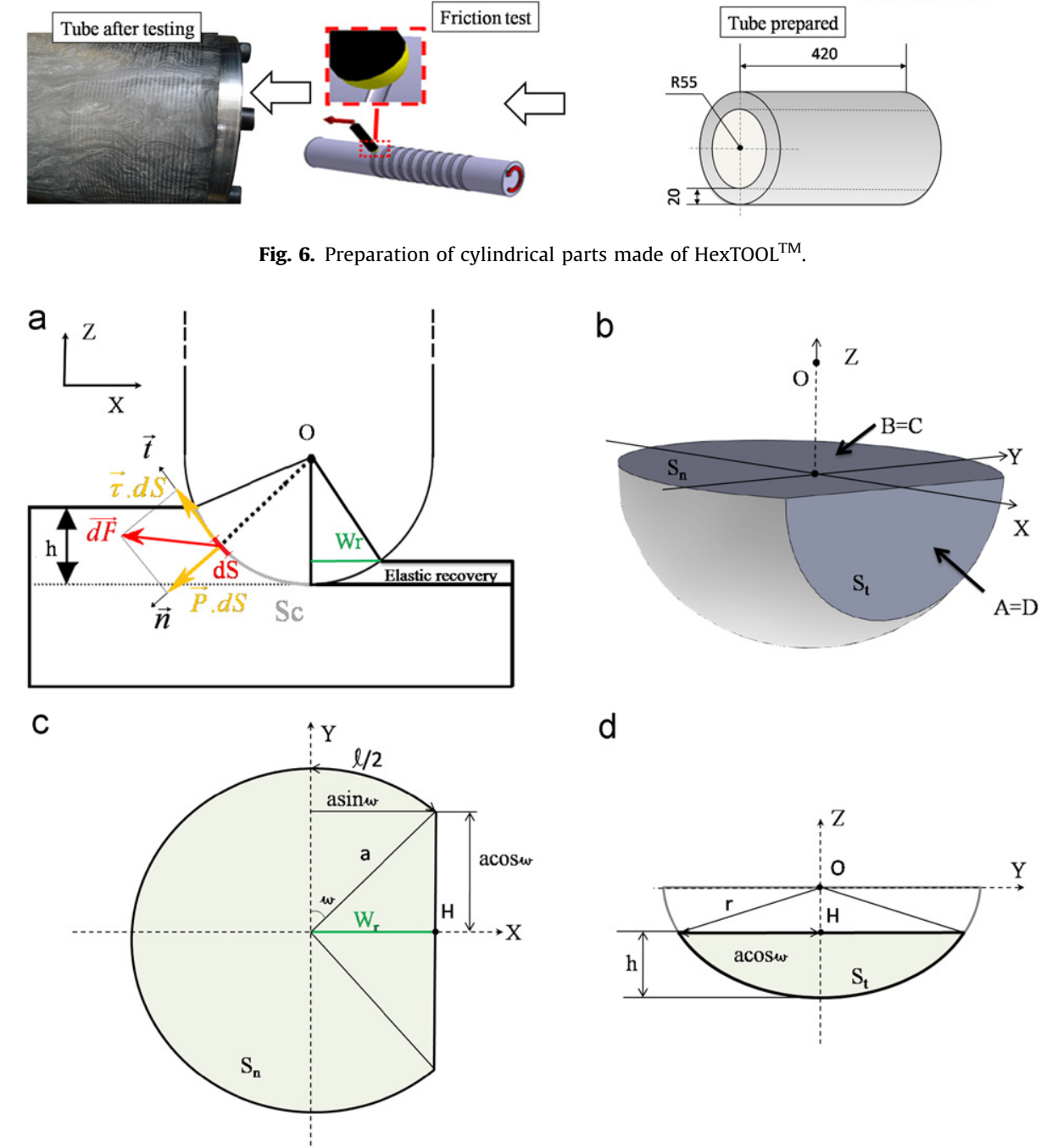

d

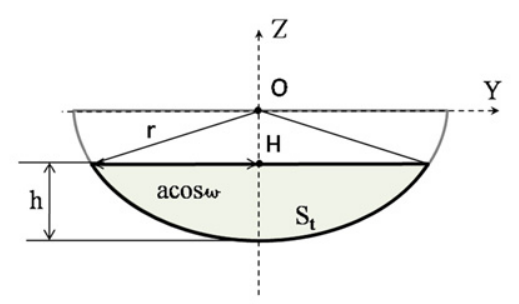

Fig. 7. (a) Illustration of analytical parameters; (b) contact surfaces; (c) normally projected contact surface; (d) tangentially projected contact surface.

the one observed on tools is obtained (Fig. 4). Therefore during friction tests, it can be considered that pins rub against a randomly structured composite material.

\subsection{Design of experiments}

In this work, two variables have been investigated:

- A range of sliding velocities: $10-120 \mathrm{~m} / \mathrm{min}$. These values have been chosen in accordance with current practice in dry milling of such workmaterials.

- Two kinds of pin: an uncoated carbide pin (the reference) and a pin coated with a $2 \mu \mathrm{m}$ layer TiN coating obtained by Physical Vapor Deposition.

Each test configuration has been replicated at least three times. Each friction test has $20 \mathrm{~s}$ duration approximately.

\subsection{Estimation of interfacial friction coefficient}

The apparent friction coefficient previously introduced in Eq. (1) can be decomposed into two components [23]

$\mu_{\text {app }}=\frac{F_{t}}{F_{n}}=\mu_{a d h}+\mu_{\text {def }}$

where $\mu_{a d h}$ is the adhesive contribution and $\mu_{d e f}$ is the deformation contribution made up of elastic and plastic partitions.

To extract the part of adhesion and deformation from the apparent friction coefficient, it is possible to rely on an analytical solution developed by Lafaye et al. [24,25] (Fig. 7). This model depends on real contact material properties taking into account the elastic recovery. In this approach, the pin is considered as infinitely rigid and the workmaterial is supposed to be elastoplastic. 
For each point of the contact surface, an elementary mechanical action is considered, which can be decomposed into two parts, an elementary contact pressure:

$\vec{P} d S=P d S \vec{n}$

and an elementary tangential force

$\vec{\tau} d S=\tau d S \vec{t}$

which combine to yield the elementary resulting force

$\overrightarrow{d F}=P d S \vec{n}+\tau d S \vec{t}$

and eventually the resulting force acting on surface Sc

$\vec{F}=\int_{S c} \overrightarrow{d F}$

where $\vec{n}$ and $\vec{t}$ are, respectively, the normal and the tangential unit vector of the considered elementary surface, Sc is the effective contact surface area, which can be $S t$ or $S n$ standing for the contact surface projection respectively in planes $x y$ and $y z$. The interfacial friction coefficient (adhesive friction coefficient) $\mu_{\text {adh }}$ is defined by

$\mu_{a d h}=\frac{\tau}{P}$

Thus, macroscopic normal and tangential forces, which are measured during friction tests, are the sum of elementary mechanical actions:

$\overrightarrow{F n}=(\vec{F} \cdot \vec{Z}) \cdot \vec{Z}=\int_{S c}(P d S \vec{n} \cdot \vec{Z}+\tau d S \vec{t} \cdot \vec{Z}) \cdot \vec{Z}$

$\overrightarrow{F t}=(\vec{F} \cdot \vec{X}) \cdot \vec{X}=\int_{S c}(P d S \vec{n} \cdot \vec{X}+\tau d S \vec{t} \cdot \vec{X}) \cdot \vec{X}$

These forces can be also written as

$\overrightarrow{F n}=(B P-D \tau) \cdot \vec{Z}$

$\overrightarrow{F t}=(A P+C \tau) \cdot \vec{X}$

with

$A=D=\left|\int_{S C}(d S \vec{n} \cdot \vec{X})\right|=\left|\int_{S C}(d S \vec{t} \cdot \vec{Z})\right|:$

measure of the projection of the contact surface Sc along $\vec{X}$,

$B=C=\left|\int_{S C}(d S \vec{n} \cdot \vec{Z})\right|=\left|\int_{S C}(d S \vec{t} \cdot \vec{X})\right|:$

measure of the projection of the contact surface $S c$ along $\vec{Z}$.

The contact area $S_{c}$ is the sum of the front area (half of the disc with radius $R$ ) and the rear area (part of the rear half disc). These projected areas (Fig. 7c and d) are calculated using the analytical solution presented in [24] for spherical tip with elastic recovery.

$S_{n}=(\pi+2 \omega+\sin 2 \omega) a^{2} / 2$

where $\omega$ is the rear contact angle, $a$ is the contact radius

$S_{t}=\left(R^{2}-a^{2} \sin ^{2} \omega\right) \sin ^{-1}(a \cos \omega / r)-a \cos \omega \sqrt{R^{2}-a^{2}}$

where $r=\sqrt{R^{2}-a^{2} \sin ^{2} \omega}$ is the radius of projected area, $R$ the radius of the spherical tip.

Therefore, the apparent friction coefficient may be written as a function of the adhesive friction coefficient:

$\mu_{a p p}=\frac{\left\|\overrightarrow{F_{t}}\right\|}{\left\|\overrightarrow{F_{n}}\right\|}=\frac{A P+C \tau}{B P-D \tau}=\frac{A+C \mu_{a d h}}{B-D \mu_{a d h}}$

Finally, the adhesive friction coefficient can be calculated, based on the effective contact area estimated from experimental measurements, as follows:

$\mu_{a d h}=\frac{B \mu_{a p p}-A}{C+D \mu_{a p p}}$

\section{Results and discussion}

Table 1 summarizes the experimental data obtained in the present work. Fig. 8 outlines the image obtained by binocular microscope observation of a pin surface, presenting an example of the real contact area for velocity of $60 \mathrm{~m} / \mathrm{min}$, where it can be clearly noticed the shape of the normally projected contact area with the elastic recovery. Table 2 reports the experimental measurements of the contact radius and the rear distance $\left(W_{r}\right)$ for $10 \mathrm{~m} / \mathrm{min}, 60 \mathrm{~m} / \mathrm{min}$ and $120 \mathrm{~m} / \mathrm{min}$.

\subsection{Identification of a friction model}

Fig. 9 depicts the evolution of the friction coefficients versus sliding velocity for TiN coated carbide pins. On the one hand, it is remarkable to see that apparent friction coefficients $\mu_{\text {app }}$ are rather low $(0.1 \rightarrow 0.25)$ compared with friction coefficients during metal cutting whatever the workmaterial/cutting tool material are. For instance $[21,22]$ report values in the range 0.5 for the AISI4140 steel and 0.8 for the AISI316L stainless steel machined with a TiN coated carbide tool under similar sliding velocities. On the other hand, it can be noticed that the values obtained in this paper are higher than friction coefficient reported by [4] for CFRP against diamond ( $\sim 0.1$ ) for sliding velocities around $10-20 \mathrm{~m} / \mathrm{min}$. This shows that carbide leads to more adhesion than diamond against CFRP. Additionally, Ref. [26] has also shown that diamond leads to the smallest cutting forces during the machining of GFRP compared to carbide. The very low coefficient of friction is assumed to be responsible for this experimental statement. Similar observations have been made by Ref. [27] in drilling of CFRP with diamond coated carbide drills compared to uncoated carbide drills. Therefore, the higher macroscopic friction coefficient observed for carbide pins compared with diamond pins is coherent with previous observations obtained in cutting.

As mentioned previously, $\mu_{a p p}$ may be decomposed into a elasto-plastic deformation coefficient $\mu_{\text {def }}$ and an interfacial friction coefficient $\mu_{a d h}$ (also called adhesive friction coefficient). In order to extract the friction coefficient $\mu_{a d h}$, it is possible to use the analytical model presented previously. Based on our experimental results, it is possible to estimate an average value of $\mu_{\text {def }}$ and $\mu_{\text {adh }}$ for each testing situation.

Therefore, different conclusions can be extracted from this analytical approach. The model shows that the major part of the apparent friction coefficient is due to elasto-plastic deformation. It represents about $50 \%$ of the apparent friction coefficient under low sliding velocities, whereas it represents $70 \%$ under high sliding velocities. This observation is totally different from friction phenomena between steels and carbides in dry machining since the influence of plastic deformation is in that case limited to $20 \%$ in any conditions. This means that, during sliding, chemical links between carbide and HexTOOL are very limited, which is confirmed by the absence of stuck composite material on pins. These observations are in accordance with results reported by [1], who indicates that adhesion is never observed on cutting tools after machining when the matrix is not carbonized or molten.

In Fig. 9, the value of adhesive friction coefficient decreases as the velocity increases ( 0.1 for $10 \mathrm{~m} / \mathrm{min}$ to 0.02 for $120 \mathrm{~m} / \mathrm{min}$ ). The same tendency can be observed for the value of deformation friction coefficient $\mu_{\text {def, }}$, which decreases as the velocity increases ( 0.11 for $10 \mathrm{~m} / \mathrm{min}$ to 0.08 for $120 \mathrm{~m} / \mathrm{min}$ ). 
Table 1

Experimental data.

\begin{tabular}{|c|c|c|c|c|c|c|}
\hline Pin & $\begin{array}{l}\text { Sliding velocity, } \\
V \text { (m/min) }\end{array}$ & $\begin{array}{l}\text { Normal force, } \\
F_{n}(\mathrm{~N})\end{array}$ & $\begin{array}{l}\text { Friction force, } \\
F_{t}(\mathrm{~N})\end{array}$ & $\begin{array}{l}\text { Apparent friction } \\
\text { coef, } \mu_{a p p}\end{array}$ & $\begin{array}{l}\text { Heat flux transmitted } \\
\text { to pins, } \Phi_{p i n}(W)\end{array}$ & $\begin{array}{l}\text { Track width } \\
(\mathrm{mm})\end{array}$ \\
\hline Uncoated carbide & 10 & 593 & 130 & 0.22 & 16 & 1.29 \\
\hline Uncoated carbide & 10 & 596 & 133 & 0.22 & 16 & 1.41 \\
\hline Uncoated carbide & 10 & 622 & 150 & 0.24 & 16 & 1.31 \\
\hline Uncoated carbide & 30 & 597 & 100 & 0.17 & 30 & 1.17 \\
\hline Uncoated carbide & 30 & 606 & 104 & 0.17 & 35 & 1.41 \\
\hline Uncoated carbide & 30 & 617 & 113 & 0.18 & 32 & 1.35 \\
\hline Uncoated carbide & 60 & 611 & 82 & 0.13 & 42 & 1.23 \\
\hline Uncoated carbide & 60 & 609 & 87 & 0.14 & 45 & 1.36 \\
\hline Uncoated carbide & 60 & 616 & 90 & 0.15 & 48 & 1.31 \\
\hline Uncoated carbide & 80 & 608 & 75 & 0.12 & 47 & 1.28 \\
\hline Uncoated carbide & 80 & 609 & 80 & 0.13 & 51 & 1.19 \\
\hline Uncoated carbide & 80 & 614 & 81 & 0.13 & 53 & 1.23 \\
\hline Uncoated carbide & 120 & 598 & 65 & 0.11 & 56 & 1.00 \\
\hline Uncoated carbide & 120 & 611 & 71 & 0.11 & 59 & 1.18 \\
\hline Uncoated carbide & 120 & 595 & 67 & 0.11 & 58 & 1.01 \\
\hline TiN coated carbide & 10 & 615 & 126 & 0.20 & 16 & 1.18 \\
\hline TiN coated carbide & 10 & 611 & 138 & 0.22 & 15 & 1.50 \\
\hline TiN coated carbide & 10 & 595 & 126 & 0.21 & 15 & 1.45 \\
\hline TiN coated carbide & 30 & 604 & 103 & 0.17 & 33 & 1.16 \\
\hline TiN coated carbide & 30 & 612 & 107 & 0.17 & 33 & 1.32 \\
\hline TiN coated carbide & 30 & 600 & 108 & 0.18 & 34 & 1.47 \\
\hline TiN coated carbide & 60 & 612 & 85 & 0.14 & 44 & 1.32 \\
\hline TiN coated carbide & 60 & 607 & 86 & 0.14 & 46 & 1.19 \\
\hline TiN coated carbide & 60 & 609 & 90 & 0.15 & 49 & 1.06 \\
\hline TiN coated carbide & 80 & 618 & 81 & 0.13 & 51 & 1.07 \\
\hline TiN coated carbide & 80 & 609 & 77 & 0.13 & 50 & 1.30 \\
\hline TiN coated carbide & 80 & 615 & 83 & 0.13 & 54 & 1.36 \\
\hline TiN coated carbide & 120 & 609 & 69 & 0.11 & 57 & 1.32 \\
\hline TiN coated carbide & 120 & 611 & 67 & 0.11 & 58 & 1.55 \\
\hline TiN coated carbide & 120 & 612 & 71 & 0.12 & 63 & 1.52 \\
\hline
\end{tabular}

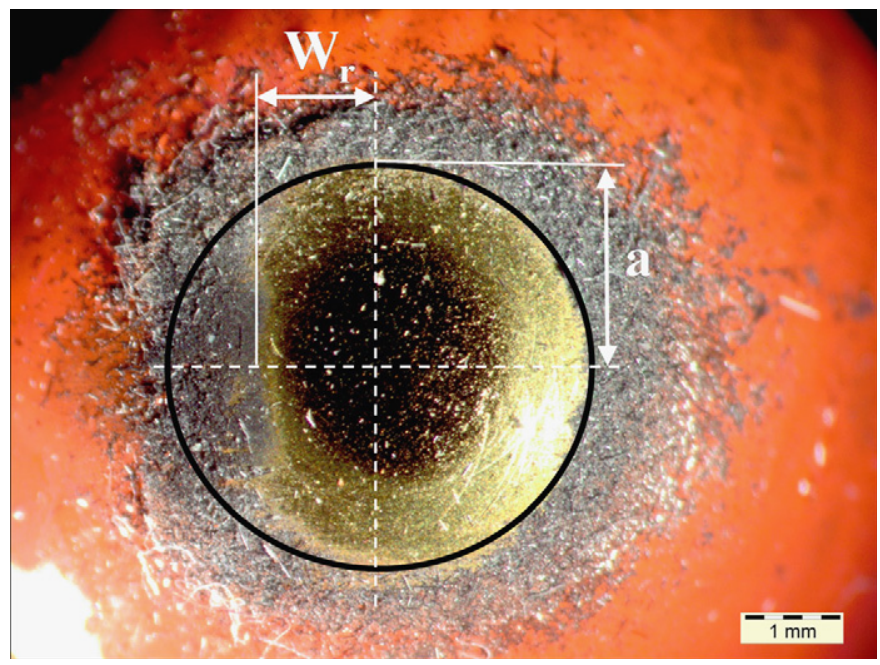

Fig. 8. Example of contact zones on pins ( $V=60 \mathrm{~m} / \mathrm{min}): a=2.14 \mathrm{~mm}, W_{r}=0.749 \mathrm{~mm}$.

Table 2

Experimental data obtained by binocular microscope for three different sliding velocities.

\begin{tabular}{llll}
\hline Pin & $\begin{array}{l}\text { Sliding velocity, } \boldsymbol{V} \\
(\mathbf{m} / \mathbf{m i n})\end{array}$ & $\begin{array}{l}\text { Contact radius, } \boldsymbol{a} \\
\mathbf{( \mathbf { m m } )}\end{array}$ & $\begin{array}{l}\text { Rear distance, } \boldsymbol{W}_{\boldsymbol{r}} \\
(\mathbf{m m})\end{array}$ \\
\hline $\begin{array}{c}\text { TiN coated } \\
\text { carbide }\end{array}$ & 10 & 1.3 & 0.998 \\
$\begin{array}{c}\text { TiN coated } \\
\text { carbide }\end{array}$ & 60 & 1.39 & 0.749 \\
$\begin{array}{c}\text { TiN coated } \\
\text { carbide }\end{array}$ & 120 & 1.49 & 0.766 \\
\hline
\end{tabular}

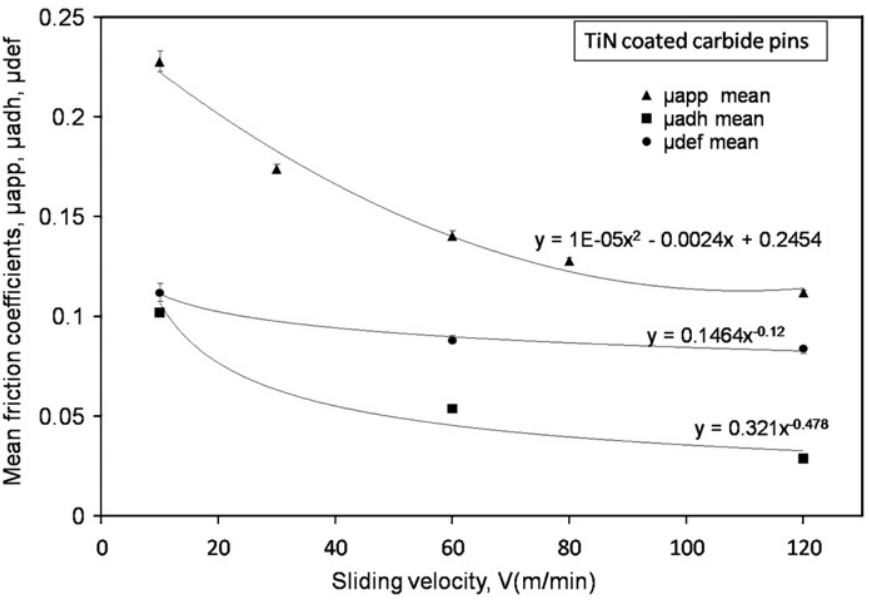

Fig. 9. Evolution of apparent, adhesion and deformation friction coefficients versus sliding velocity.

Thus, the combination of experimental results with the analytical model enables to provide data for future numerical modeling of machining operations in dry regime between CFRP and carbide:

$\mu_{a d h}=0.321 V^{-0.478}$

Fig. 10b reports the evolution of heat flux transmitted to pins $\phi_{\text {pin }}$ during friction tests. It is observed that heat flux increases with sliding velocity as expected. It should be underlined that only a percentage of the total energy $\phi_{\text {tot }}$, dissipated during tests is transmitted to pins. An amount of heat remains in the workmaterial $\phi_{\text {workmaterial }}$. In a first step of analysis, it is possible to 
a

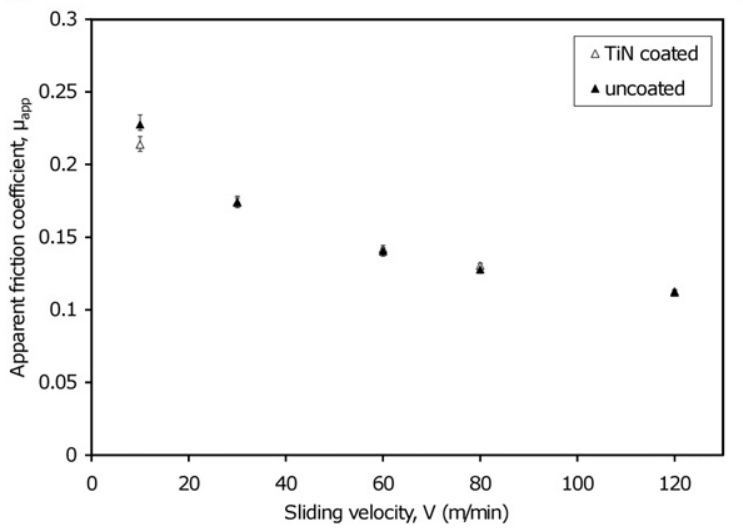

b

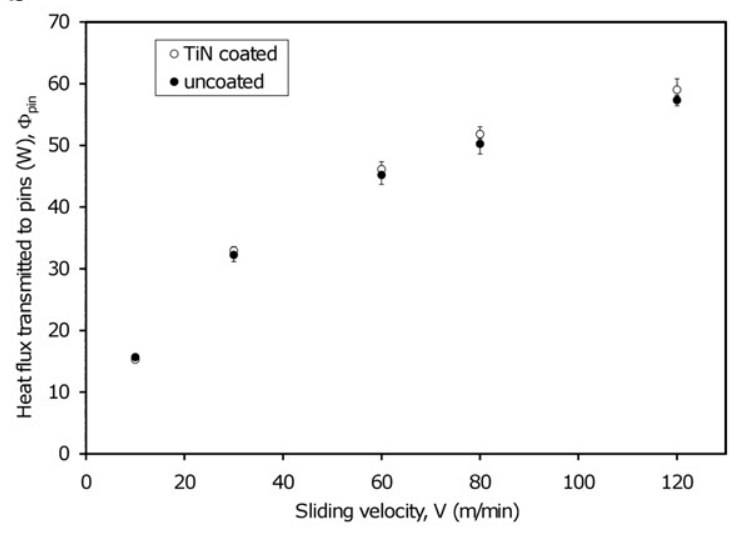

C

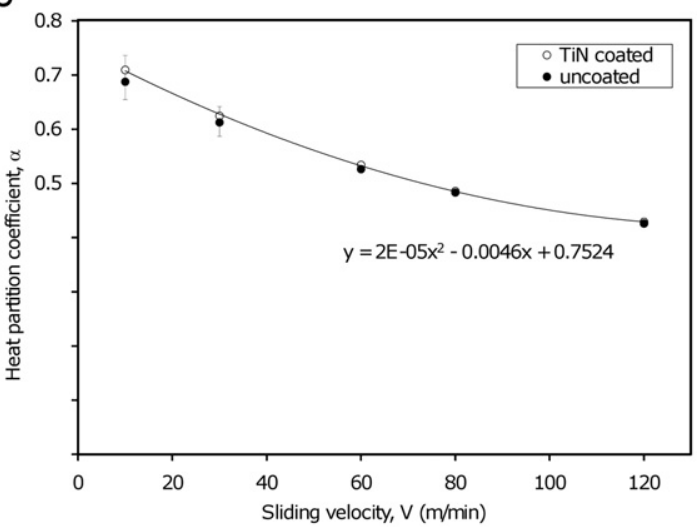

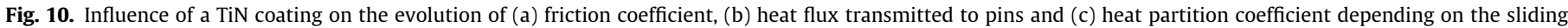
velocity.

estimate the total energy $\phi_{\text {tot }}$ by

$\phi_{\text {tot }}=F_{t} V$

where $F_{t}$ is the tangential force $(\mathrm{N})$ and $V$ is the macroscopic sliding velocity $(\mathrm{m} / \mathrm{s})$.

By assuming that all frictional energy is transformed into heat, a heat partition coefficient $\alpha$ at the interface can be estimated by

$\alpha=\frac{\phi_{\text {pin }}}{\phi_{\text {tot }}}$

It means that $\alpha$ fraction of energy is transmitted to pins, whereas the workmaterial supports $(1-\alpha)$ of this energy. Theoretically, $\alpha$ is equal to $\xi$ in the case of infinite media, which is defined in Eq. (18). $\xi$ depends on the effusivity of the two materials when sliding at a very low velocity (some $\mathrm{mm} / \mathrm{s}$ ).

$\zeta=\frac{e_{\text {pin }}}{e_{\text {pin }}+e_{\text {workmaterial }}} \sim 0.83$ at $20^{\circ} \mathrm{C}$

with pin's effusivity:

$e_{\text {pin }}=\sqrt{\lambda_{\text {pin }} \rho_{\text {pin }} C_{\text {pin }}} \sim 11350\left(\mathrm{Nm}^{-1}{ }^{\circ} \mathrm{C}^{-1} \mathrm{~s}^{-1 / 2}\right)$ at $20^{\circ} \mathrm{C}$

where $\lambda$ is the thermal conductivity $\left(\mathrm{W} \mathrm{m}^{-1}{ }^{\circ} \mathrm{C}^{-1}\right), \rho$ is the density $\left(\mathrm{kg} \mathrm{m}^{-3}\right), C$ is the specific heat $\left(\mathrm{J} \mathrm{kg}^{-1}{ }^{\circ} \mathrm{C}^{-1}\right)$ and the workmaterial's effusivity:

$e_{\text {workmaterial }}=\sqrt{\lambda_{\text {workmaterial }} \rho_{\text {workmaterial }} C_{\text {workmaterial }}}$

$$
\sim 2333\left(\mathrm{Nm}^{-1}{ }^{\circ} \mathrm{C}^{-1} \mathrm{~s}^{-1 / 2}\right) \text { at } 20^{\circ} \mathrm{C}
$$

Unfortunately, for dynamic sliding interfaces, the standard thermal model is no more valid. Therefore, Fig. 10c reports the experimental values of the heat partition coefficient $\alpha$ as a function of sliding velocity. One can notice that $\alpha$ decreases with sliding velocity which is a similar trend as the one observed for metal [22]. Finally, a model describing the evolution of the heat partition coefficient depending on sliding velocities is presented in the following form (22):

$\alpha=2.10^{-5} V^{2}-4 \times 10^{-3} V+0.75$

\subsection{Influence of cutting tool coatings}

Fig. 10 outlines the results obtained for uncoated and TiN coated carbide pins. The TiN coating is the most common coating deposited on carbide tools. The results show that this coating is not able to modify neither the friction coefficient, nor the heat flux transmitted to pins and, as a consequence, nor the heat partition coefficient. It can be concluded that a TiN coating has the same tribological properties than a carbide substrate against such composite materials.

\section{Conclusions}

The input data required to the numerical simulation models of the cutting process are the true contact area, the heat partition and the friction coefficients. A new original set-up presenting the rotary open tribometer has been developed in the paper. This tribometer enables to conduct friction tests up to $120 \mathrm{~m} / \mathrm{min}$ under high contact pressure with continuously regenerated contact surface. The intensive contact between carbide pins and HexTOOL ${ }^{\mathrm{TM}}$ CFRP parts leads to a strong elasto-plastic deformation in parallel to the friction at the interface. 
An analytical model has been proposed in order to extract the interfacial friction coefficient from macroscopic measurements. This model considers the real contact depending on material properties taking into account the elastic recovery of this composite material. The binocular microscope observation of pin's surface is done in order to determine the real contact area. Based on this new experimental set-up combined with this analytical model, the true local friction coefficient at the interface between a tip and HexTOOL ${ }^{\mathrm{TM}}$ material is deduced, during the machining of with carbide cutting tool. It has been shown that friction coefficient is much lower than those for metal cutting. However friction coefficient decreases with sliding velocity. Moreover, a model of friction has been identified in order to be implemented in any cutting model. The heat partition coefficient at the interface has also been investigated. It has been shown that it decreases as sliding velocity increases and a model has been identified, which can easily be fit into FE simulations, these data are the real help for the FE of composite cutting models. Finally, it has been shown that friction coefficient is not sensitive to the presence of a TiN coating deposited on pins.

\section{References}

[1] Teti R. Machining of composite materials. CIRP Annals-Manufacturing Technology 2002;51/2:611-34

[2] Klocke F, Würtz C. The use of PCD tools for machining fibers reinforced materials. In: Proceedings of the ECCM, 8, Naples (Italy); 3-6 June 1998. p. 509-15.

[3] Ferreira JR, Coppini NL, Miranda GWA. Machining optimization in composite fibre reinforced composite materials. Journal of Materials Processing Technology 1999;92-93:135-40.

[4] Mondelin A, Furet B, Rech J. Characterisation of friction properties between a laminated carbon fibers reinforced polymer and a monocrystalline diamond under dry or lubricated conditions. Tribology International 2010;43:1665-73.

[5] Venu Gopala Rao G, Mahajan P, Bhatnagar N. Micro-mechanical modelling of machining of FRP composites cutting force analysis. Composites Science and technology 2007;67:579-93.

[6] Zhang LC. Cutting composite: a discussion on mechanics modelling. Journal Materials Processing Technology 2009;209:4548-52.

[7] Santiuste C, Soldani X, Miguélez MH. Machining FEM model of long fibre composites for aeronautical components. Composite structures 2010;92:691-8.

[8] Nayak D, Bhatnagar N, Mahajan P. Machining studies of UD-GFRP composites. Part-1. Effect of geometrical and process parameters. Machining Science and Technology 2005;9:481-501.

[9] Nayak D, Bhatnagar N, Mahajan P. Machining studies of UD-GFRP composites. Part-2. Finite element analysis. Machining Science and Technology 2005;9: 503-28.
[10] Zitoune R, Collombet F, Lachaud F, Piquet R, Pasquet P. Experiment-calculation comparison of the cutting conditions representative of the long fibre composite drilling phase. Composites Sciences and Technology 2005;65: 455-66.

[11] Mahdi M, Zhang L. A finite element model for the orthogonal cutting of fibre reinforced composite materials. Journal of Materials Processing Technology 2001;113:373-7.

[12] Ramesh MV, Seetharamu KN, Ganesan N, Shivkumar MS. Analysis of machining of FRPs usinage FEM. International Journal of Machine Tools and Manufacture 1998;38:1531-49.

[13] Iliescu D, Gehin D, Iordanoff I, Girot F, Gutteriez ME. A discrete element method for the simulation of CFRP cutting. Composites Science and Technology 2010;70:73-80.

[14] Arola D, Ramulu M. Orthogonal cutting of fiber-reinforced composites: a finite element analysis. International Journal of Mechanical Sciences 1997 39:597-613.

[15] Lasri L, Nouari M, El Mansori M. Modeling of chip separation in machining unidirectional FRP composites by stiffness degradation concept. Composites Science and Technology 2009;69:684-92.

[16] Mkaddem A, El Mansori M. Finite element analysis when machining UGFreinforced PMCs plates: chip formation, crack propagation and induceddamage. Materials \& Design 2009;30/8:3295-302.

[17] Tripathy BS, Furey MJ. Triboligical behavior of unidirectional graphite-epoxy and carbon-PEEK composites. Wear 1993;162/164:385-96.

[18] Matsunaga S, Matsubara T, Wang W-X, Takao Y. Effects of reciprocation number on the friction behaviors of carbon/epoxy for various fiber orientations and high contact pressures. In: Proceedings of the ICCM-13, Beijing (China); 2001, p. ID 1446.

[19] Abrao AM, Faria PE, Campos Rubio JC, Reis P, Paulo Davim J. Drilling of fibre reinforces plastics: a review. Journal of Materials Processing Technology 2007; 186:1-7.

[20] Hedenqvist P, Olsson M. Sliding wear testing of coated cutting tool materials Tribology International 1991;23(3):143-50.

[21] Zemzemi F, Bensalem W, Rech J, Dogui A, Kapsa P. New tribometer designed for the characterization of the friction properties at the tool/chip/workpiece interfaces in machining. Tribotest 2008;14:11-25.

22] Bonnet $\mathrm{C}$, Valiorgue $\mathrm{F}$, Rech J, Hamdi $\mathrm{H}$. Improvement of the numerical modeling in orthogonal dry cutting of an AISI316L stainless steel by the introduction of a new friction model. CIRP_-Journal of Manufacturing Science and Technology 2008;1/2:114-8.

[23] Bowden FP, Tabor D. Friction and Lubrication of Solids. Oxford University Press; 1951.

24] Lafaye S, Gauthier C, Schirrer R. The ploughing friction: analytical model with elastic recovery for a conical tip with a blunted spherical extremity. Tribology Letters 2006;21/2:95-9.

[25] Lafaye S, Gauthier C, Schirrer R. A surface flow line model of a scratching tip: apparent and true local friction coefficients. Tribology International 2005;38: 113-27.

[26] Sang-Ook A, Lee ES, Noh SL. A study on the cutting characteristics of GFRP with respect to tool materials and geometries. Journal of Materials Processing Technology 1997;68:60-7.

[27] Iliescu D, Gehin D, Gutierrez ME, Girot F. Modeling and tool wear in drilling of CFRP. International Journal for Machine Tool and Manufacture 2010;50: 204-13.

[28] Hexcel Composites. HexTOOL ${ }^{\mathrm{TM}}$ User Guide, 2008. 